\title{
Correction to: Unlocking the black box: A comprehensive meta-analysis of the main determinants of within-region income inequality
}

\author{
Diana Barros ${ }^{1}$ (D) Aurora A. C. Teixeira ${ }^{2}$ (D)
}

Accepted: 1 February 2021 / Published online: 11 February 2021

(C) Springer-Verlag GmbH Germany, part of Springer Nature 2021

\section{Erratum to:}

Rev Reg Res 2021

https://doi.org/10.1007/s10037-020-00149-0

In the original publication the authors' affiliations were incompletely represented.

The complete affiliations are represented here.

The online version of the original article can be found under https://doi.org/10.1007/s10037-02000149-0.

D. Barros

barros.diana@hotmail.com

A. A. C. Teixeira

ateixeira@fep.up.pt

1 Centre for Geographical Studies, Institute of Geography and Spatial Planning (IGOT), University of Lisbon, Lisbon, Portugal

2 Faculty of Economics, CEF.UP, INESC Tec, OBEGEF, University of Porto, Porto, Portugal 